\title{
ADEQUAÇÃO DO TEOR DE CARBONO ORGÂNICO TOTAL NO CONCENTRADO DE FOSFATO BAYÓVAR POR OXIDAÇÃO TÉRMICA EM BAIXA TEMPERATURA E AVALIAÇÃO DO DESEMPENHO NA PRODUÇÃO DE ÁCIDO FOSFÓRICO EM TESTES CONTÍNUOS EM PLANTA PILOTO
}

Ruberlan Gomes da Silva ${ }^{1,2}$ Angela Nair Avelar '

\section{Resumo}

O concentrado de fosfato produzido a partir do beneficiamento do minério fosfático é utilizado industrialmente na produção de ácido fosfórico $\left(\mathrm{H}_{3} \mathrm{PO}_{4}\right)$ e de fertilizantes fosfatados, tais como, superfosfato triplo (TSP) e/ou superfosfato simples pó (SSP). O concentrado de fosfato Bayóvar contém elevado teor de carbono orgânico total, entre 6.000 a 12.000 ppm proveniente do material orgânico reliquiar dos pellets de apatita $\left(\mathrm{Ca}_{10}\left(\mathrm{PO}_{4}\right)_{6} \cdot \mathrm{X}_{2}, \mathrm{X}=\mathrm{Cl}, \mathrm{F}\right.$ ou $\mathrm{OH}-$ ). No processo de produção de ácido fosfórico a matéria orgânica é liberada para a polpa ácida, contendo principalmente $\mathrm{H}_{3} \mathrm{PO}_{4}$ e $\mathrm{CaSO}_{4} \cdot 2 \mathrm{H}_{2} \mathrm{O}$, após reação da apatita com ácido sulfúrico, o que eleva a viscosidade da polpa, reduz à taxa de filtração, forma espuma estável no reator e diminui a capacidade de produção na planta industrial. O objetivo desse estudo é apresentar e discutir os resultados dos ensaios dos tratamentos térmicos em baixas temperaturas $\left(300 \mathrm{a} 600^{\circ} \mathrm{C}\right)$, realizados em escala de laboratório em forno de leito fluidizado não contínuo, para adequação do teor de carbono orgânico para a faixa de 1.500 a 3.500 ppm, valores esses verificados nos concentrados de fosfatos comerciais de Marrocos e da Flórida. Além de comparar os principais parâmetros da rota de processo dihidrato obtidos nos ensaios contínuos em mini planta piloto com os concentrados de fosfatos Bayóvar sem tratamento térmico e após tratamento térmico.

Palavras-chave: Concentrado de fosfato; Oxidação; Carbono orgânico; Bayóvar; Ácido fosfórico; Forno de leito fluidizado.

\section{ADEQUATION OF TOTAL ORGANIC CARBON CONTENT IN THE BAYÓVAR PHOSPHATE ROCK BY OXIDATION AT LOW TEMPERATURE AND EVALUATION OF ITS PERFORMANCE IN PHOSPHORIC ACID PRODUCTION IN CONTINUOUS PILOT PLANT TEST}

\begin{abstract}
The most of phosphate rocks produced by beneficiation of phosphate ores are largely used in production of phosphoric acid $\left(\mathrm{H}_{3} \mathrm{PO}_{4}\right)$ and phosphate fertilizers, like, Triple SuperPhosphate (TSP) and Single SuperPhosphate (SSP). The Bayóvar phosphate rock contains a high content of total organic carbon, between 6,000 to 12,000ppm, from small particles of apatite $\left(\mathrm{Ca}_{10}\left(\mathrm{PO}_{4}\right)_{6} \cdot \mathrm{X}_{2}, \mathrm{X}=\mathrm{Cl}^{-}, \mathrm{F}^{-}\right.$or $\left.\mathrm{OH}^{-}\right)$pellets, which ones are liberated, in the phosphoric acid production, to acid pulp (mainly $\mathrm{H}_{3} \mathrm{PO}_{4}$ and $\mathrm{CaSO}_{4} \cdot 2 \mathrm{H}_{2} \mathrm{O}$ ) after reaction between apatite and sulphuric acid. This increases the viscosity of pulp, decreases the filtration rates, generate stable foam in the reactor and consequently reduce the production rate of Industrial Plant.The objective of this study was to present the results and discuss the effects of a low temperature thermal treatment on the behaviour of a sedimentary phosphate. The thermal treatment was effected in a batch fluidized
\end{abstract}

'Centro de Desenvolvimento Mineral da VALE, Santa Luiza, MG, Brasil.E-mail: ruberlan.silva@vale.com

${ }^{2}$ Departamento de Engenharia Química, Universidade Federal de Minas Gerias - UFMG, Belo Horizonte, MG, Brasil.

${ }^{3}$ Vale Fertilizantes, Cubatão, SP, Brasil.

${ }^{4}$ P Smith Associate Ltda., Araxá, MG, Brasil.

2176-1523 (c) 2017 Associação Brasileira de Metalurgia, Materiais e Mineração. Publicado pela ABM. Este é um artigo de acesso aberto distribuído sob os termos da licença Creative Commons CC BY-NC-ND (Attribution-NonCommercial-NoDerivs) - https:// creativecommons.org/licenses/by-nc-nd/4.0\%. 
bed kiln in order to reduce the total organic carbon level to the order of I,500 to 3,500 ppm, commonly checked in the commercial phosphate rocks from Morocco and Florida. The behaviour of the Bayóvar phosphate in the production of phosphoric acid was evaluated in comparative continuous pilot-plant tests with results from the non-treated and the thermally treated Bayóvar phosphate.

Keywords: Phosphate rock; Oxidation; Organic carbon; Bayóvar; Phosphoric acid; Fluidized bed kiln.

\section{INTRODUÇÃO}

Os principais fertilizantes fosfatados consumidos no Brasil são o superfosfato triplo (TSP), superfosfato simples (SSP), fosfato monoamônio (MAP) e fosfato diamônio (DAP) [I]. Com exceção do SSP, os demais usam como principal matéria-prima o ácido fosfórico. A apatita é o principal mineral encontrado nos concentrados de fosfatados enriquecidos em $\mathrm{P}_{2} \mathrm{O}_{5}$, matéria-prima usada na produção de ácido fosfórico através da reação com ácido sulfúrico [2]. A presença de impurezas, entre elas, carbono orgânico na composição dos concentrados afeta negativamente o desempenho das unidades industriais produtoras de ácido fosfórico, exigindo a necessidade de uso de aditivos específicos, tais como antiespumantes, floculantes e modificadores de hábito cristalino para melhorar as condições de operação [3-6]. O concentrado de fosfato Bayóvar contém alto teor de carbono orgânico total em sua composição variando entre 6.000 a I 2.000 ppm [7], enquanto que os de Marrocos e da Flórida contém entre 1.500 e 3.500 ppm. O estudo descrito por SILVA et al. [8] mostrou que a redução do teor de carbono orgânico total na composição do concentrado de fosfato Bayóvar, através de tratamento térmico em alta temperatura $\left(800^{\circ} \mathrm{C}\right)$, para valores menores que $500 \mathrm{ppm}$ não apresentou viabilidade econômica, devido ao aumento considerável no custo de produção (+US\$ 32/t concentrado de fosfato) e técnica porque diminuiu a recuperação de $\mathrm{P}_{2} \mathrm{O}_{5}$ e a taxa de filtração da polpa fosfórica. Uma alternativa é reduzir o teor de carbono orgânico no concentrado para a faixa de 1.500 a 3.500 ppm por tratamento térmico em uma temperatura menor $\left(<800^{\circ} \mathrm{C}\right)$ para reduzir o consumo de energia térmica [8] e minimizar o efeito deletério causado pela calcinação em alta temperatura, a drástica redução da área superficial do fosfato, bem como sua reatividade. Esse estudo tem como objetivo apresentar e discutir os resultados dos ensaios dos tratamentos térmicos em baixas temperaturas $\left(300 \mathrm{a} 600^{\circ} \mathrm{C}\right)$, realizados em escala de laboratório em forno de leito fluidizado não contínuo, para adequar o teor de carbono orgânico do concentrado para a faixa de 1.500 a 3.500 ppm, além de comparar os principais parâmetros da rota de processo dihidrato através de ensaios contínuos em mini planta piloto com os concentrados de fosfatos Bayóvar sem tratamento térmico e após tratamento térmico.

\section{MATERIAL E METÓDOS}

Os $200 \mathrm{~kg}$ da amostra do concentrado de fosfato Bayóvar foi homogeneizada e quarteada em carrossel em alíquotas de $4 \mathrm{~kg}$. Os ensaios de calcinação no forno de leito fluidizado não contínuo foram realizados com alíquotas de
$400 \mathrm{~g}$ de amostra. O intervalo de temperatura de calcinação de 300 a $600^{\circ} \mathrm{C}$ foi inicialmente avaliada com objetivo de identificar a melhor temperatura para a obtenção de um concentrado submetido a tratamento térmico com teor de carbono orgânico total entre 1.500 a 3.500 ppm. Após definição da melhor temperatura, foram produzidos $100 \mathrm{~kg}$ de concentrado tratado termicamente para ser usado no ensaio contínuo em mini planta piloto de ácido fosfórico, com duração total de aproximadamente $100 \mathrm{~h}(\sim \mathrm{lgg} / \mathrm{h}$ de alimentação). Para comparação, também foi realizado ensaio contínuo em mini planta piloto com concentrado sem tratamento térmico e os parâmetros de processo foram comparados.

\section{I Métodos Analíticos}

As amostras sólidas são secas em estuda $100^{\circ} \mathrm{C}$ por 2 horas e moídas $(<0,104 \mathrm{~mm})$. Os teores de $\mathrm{P}_{2} \mathrm{O}_{5}, \mathrm{CaO}, \mathrm{MgO}, \mathrm{Al}_{2} \mathrm{O}_{3}, \mathrm{Fe}_{2} \mathrm{O}_{3}, \mathrm{SiO}_{2}, \mathrm{Cd}$ e $\mathrm{SrO}$ foram obtidos usando-se a técnica analítica de espectrometria de emissão ótica com plasma indutivamente acoplado (ICP-OES), sendo a abertura das amostras por fusão com carbonato $\mathrm{e}$ metaborato de sódio para determinação de $\mathrm{P}_{2} \mathrm{O}_{5}, \mathrm{CaO}, \mathrm{MgO}$, $\mathrm{Al}_{2} \mathrm{O}_{3}, \mathrm{Fe}_{2} \mathrm{O}_{3}, \mathrm{eSiO}$, e tratamento prévio com ácido nítrico para as determinações de $\mathrm{Cd}$ e $\mathrm{SrO}$. Os teores de cloretos foram determinados por titulação com nitrato de prata; o sulfato por precipitação com $\mathrm{BaCl}_{2}$; o enxofre total por combustão direta e leitura em infravermelho $\mathrm{LECO} ; \circ \mathrm{Na}_{2} \mathrm{O}$ e $\mathrm{K}_{2} \mathrm{O}$ usando-se também o ICP-OES, sendo as solubilizações das amostras realizadas com ácido nítrico e ácido fluorídrico. $\mathrm{O}$ teor de carbono orgânico foi determinado por oxidação com dicromato de potássio em solução sulfúrica [8] e flúor por eletrodo de íons específicos. As composições mineralógicas das amostras foram determinadas por difração de raios $X$, sendo as amostras também analisadas usando-se microscópio eletrônico de varredura (MEV) e QEMSCAN, onde foram avaliadas a composição modal e suas associações mineralógicas. A determinação da área superficial específica (SSA, specific surface area) foi realizada no aparelho NOVA I000e, marca Quantachrome, que utiliza o princípio da adsorção do gás nitrogênio na superfície do sólido, através da técnica B.E.T. Os teores de $\mathrm{CO}_{2}$ foram determinados pela solubilização da amostra em ácido clorídrico e medições dos volumes de gás desprendido.

\subsection{Equipamentos}

Os ensaios de oxidação térmica foram realizados no forno de leito fluidizado FORTELAB Indústria de Fornos Elétricos LTDA, com diâmetro do tubo cilíndrico de mulita de $63 \mathrm{~mm}$. Os ensaios contínuos em miniplanta piloto de ácido fosfórico foram executados em um tanque cilíndrico 
(reator) fabricado em aço $304 \mathrm{~L}$, monocuba com volume útil de 9 litros e com volume específico de $\mathrm{I}, 5 \mathrm{~m}^{3} / \mathrm{t} \mathrm{P}_{2} \mathrm{O}_{5} / \mathrm{dia}$, teor de sulfato total no ácido fosfórico entre I,4\% a I,8\%, contendo $32 \%$ a $34 \%$ de sólidos e $24,0 \%$ a $27,0 \%$ de $\mathrm{P}_{2} \mathrm{O}_{5}$ no ácido fosfórico produzido. A dosagem volumétrica do concentrado de fosfato foi realizada pelo equipamento da BRABENDER modelo DSR28 com precisão de $\pm 3 \%$. Foram usadas bombas peristálticas da MASTERFLEX e da WATSON MARLOW para dosagens dos reagentes líquidos (ácido sulfúrico, ácido fosfórico de reciclo e emulsão do antiespumante), com precisões de $\pm 4 \%$. Os ensaios de filtração foram realizados com funil com área seccional de $0,0096 \mathrm{~m}^{2}$, com tela filtrante fornecida pela SOLAFT (Tecido Filtrante I I363, 100\% Poliéster, 5 × I Broken Twill, $1000 \mathrm{~g} / \mathrm{m}^{2}$, monifilamento, I50-350 cfm/ $/ \mathrm{t}^{2} @ \mathrm{I} / 2$ "WG nominal) e vácuo controlado com válvula de ajuste fino.

\subsection{Reagentes}

A amostra de concentrado de fosfato Bayóvar usada no estudo foi produzida na Unidade Industrial da Vale Fertilizantes no Peru a partir do beneficiamento dos minérios extraídos das camadas I a 5 [8] e conforme o diagrama de blocos do beneficiamento do minério ROM descrito por Baldoino [3]. Os $260 \mathrm{~kg}$ usados nos ensaios foram uma fração representativa de um lote industrial produzido na Unidade Industrial do Peru em oito de Junho de 2014, e que corresponde a uma mistura de $70 \%$ em massa da produção direta na Unidade Industrial e $30 \%$ em massa oriunda do estocado em pilha e/ou silo. A fração correspondente da produção direta foi obtida a partir do processamento industrial dos minérios lavrados da camada I $(28 \% \mathrm{~m} / \mathrm{m})$, camada $2(36 \% \mathrm{~m} / \mathrm{m})$ e camada $3(36 \% \mathrm{~m} / \mathrm{m})$.

Foram usados aditivos nos ensaios contínuos na mini planta piloto de ácido fosfórico, são eles: (i) aditivo de filtração FLONEX $912 \mathrm{SH}$ fornecido pela empresa SNF do Brasil LTDA, (ii) aditivo para complexação do flúor, caulim da empresa BRASCLAY Empresa de Mineração LTDAe (iii) aditivo antiespumante LIOVAC I90I da MIRACEMA NUODEX Indústria Química LTDA.

\section{RESULTADOS E DISCUSSÃO}

As caracterizações das amostras e dos produtos e os resultados obtidos nos ensaios de oxidação térmica no forno e de solubilização com ácido sulfúrico na mini planta piloto de ácido fosfórico são apresentados a seguir.

\section{I Caracterização das Amostras}

A Tabela I apresenta a composição química do concentrado de fosfato Bayóvar usado nos ensaios. Observa-se que o teor de $\mathrm{P}_{2} \mathrm{O}_{5}$ total foi de $30,18 \%$, com razão $\mathrm{CaO} / \mathrm{P}_{2} \mathrm{O}_{5}$ de $\mathrm{I}, 49$, altos teores de $\mathrm{Al}_{2} \mathrm{O}_{3}(\mathrm{I}, 20 \%)$, de $\mathrm{Na}_{2} \mathrm{O}(\mathrm{I}, 47 \%)$ e de enxofre total $(2, \mathrm{I} \mid \mathrm{H})$, sendo que $23 \%$ do enxofre total estima-se que esteja na forma de sulfetos inorgânicos ou orgânicos. $O$ teor de enxofre na forma de sulfetos foi calculado através de balanço de massa entre o teor de enxofre total $(2,11 \%)$ e o teor de enxofre na forma de sulfatos $(4,89 \%$ de sulfato ou I, $63 \%$ de enxofre na forma de sulfatos). $O$ teor de carbono orgânico foi de $8.323 \mathrm{ppm}$, valor fora da faixa desejada, I.500 a $3.500 \mathrm{ppm}$. A área superficial específica, medida pela técnica B.E.T., foi de $27 \mathrm{~m}^{2} / \mathrm{g}$. O teor de $\mathrm{CO}_{2}$ analisado foi de $4,8 \%$.

A amostra de caulim usada, nos ensaios contínuos em mini planta piloto de ácido fosfórico, para melhorar as condições de cristalização do fosfogesso e diminuir o efeito corrosivo do flúor apresentou a seguinte composição química: $40,8 \% \mathrm{Al}_{2} \mathrm{O}_{3}$, $0,53 \% \mathrm{Fe}_{2} \mathrm{O}_{3}, 47,9 \% \mathrm{SiO}_{2},<0,06 \% \mathrm{CaO},<0,02 \% \mathrm{MgO}$, $<0,10 \% \mathrm{P}_{2} \mathrm{O}_{5}$ e $<100 \mathrm{ppm}$ de flúor. Os minerais contendo sílica e alumina em suas composições são recomendados como modificadores de hábitos cristalinos [6]. A presença de sílica solúvel auxilia na passivação do efeito corrosivo do flúor devido à complexação do flúor na forma de $\mathrm{SiF}_{6}{ }^{2-}[4]$.

\subsection{Ensaios de Oxidação Térmica em Forno de Leito Fluidizado}

A Figura I mostra os teores de carbono orgânico total dos concentrados de fosfatos Bayóvar sem tratamento e após tratamento térmico obtidos nos ensaios em Forno de Leito Fluidizado com vazão de ar de alimentação de $10 \mathrm{~L} / \mathrm{min}\left(20^{\circ} \mathrm{C}\right)$. A Figura 2 e a Figura 3 apresentam as áreas superficiais específicas (SSA B.ET.) e as razões de massa do $\mathrm{P}_{2} \mathrm{O}_{5}$ solúvel em solução de ácido cítrico e o $\mathrm{P}_{2} \mathrm{O}_{5}$ total. $O$ tempo de residência igual a zero corresponde aos valores iniciais verificados no concentrado de fosfato Bayóvar sem tratamento térmico. Observa-se que não há variações significativas nos teores de carbono orgânico total nos concentrados de fosfatos após tratamento térmico obtidos nas temperaturas de calcinação de $450^{\circ} \mathrm{C}$ (média de $2980 \mathrm{ppm}$ ) e $600^{\circ} \mathrm{C}$ (média $2745 \mathrm{ppm}$ ) a partir de 20 minutos de oxidação térmica. Um tempo de residência no forno de 20 minutos

Tabela I. Composição química do concentrado de fosfato Bayóvar sem tratamento térmico (base seca)

\begin{tabular}{|c|c|c|c|c|c|c|c|c|c|c|c|c|c|}
\hline 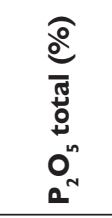 & 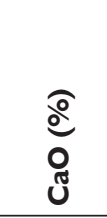 & $\begin{array}{l}\text { o } \\
0 \\
0 \\
\Sigma \\
\Sigma\end{array}$ & 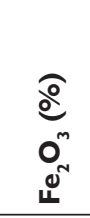 & 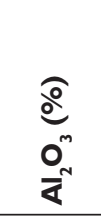 & 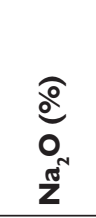 & 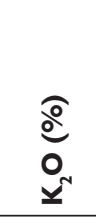 & $\frac{\varrho}{\circ}$ & 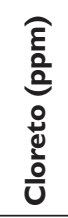 & $\begin{array}{l}\hat{\varepsilon} \\
\text { 응 } \\
\text { ర }\end{array}$ & $\begin{array}{l}a \\
\text { o } \\
\text { ทे }\end{array}$ & 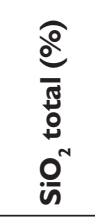 & $\begin{array}{l}\bar{J} \\
\stackrel{2}{4} \\
\text { u }\end{array}$ & 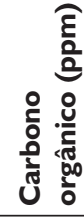 \\
\hline $30,18 \pm$ & $45,05 \pm$ & 0,67 & 0,74 & 1,20 & $\mathrm{I}, 47$ & 0,20 & 2,54 & 666 & 43 & $0,28 \pm$ & 5,42 & 2,11 & 8323 \\
\hline 0,17 & 0,35 & $\pm 0,01$ & $\pm 0,01$ & $\pm 0,27$ & $\pm 0,03$ & $\pm 0,01$ & $\pm 0,04$ & \pm 6 & \pm 1 & 0,01 & $\pm 0,31$ & $\pm 0,04$ & \pm 228 \\
\hline
\end{tabular}




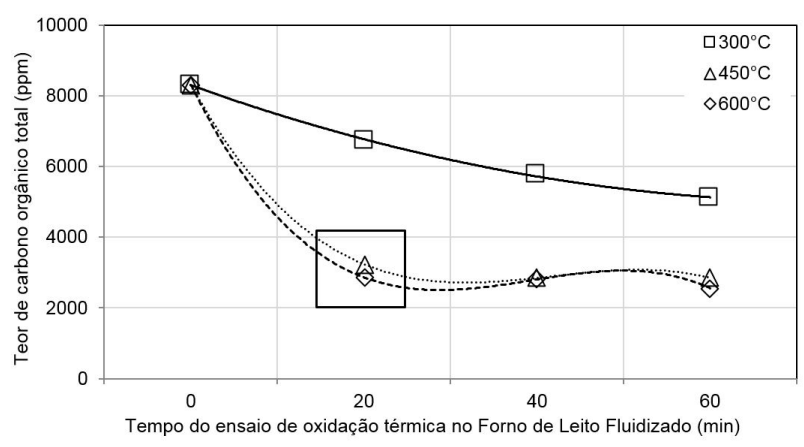

Figura I. Teores de carbono orgânico total nos concentrados de fosfato Bayóvar sem tratamento e após tratamento térmico no forno de leito fluidizado em várias temperaturas.

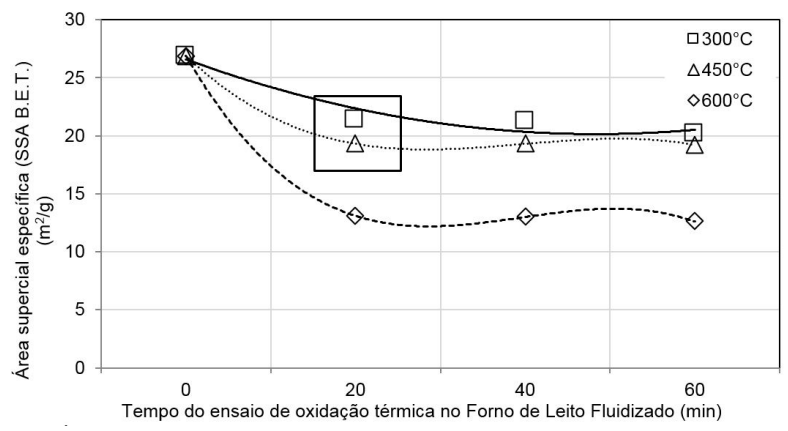

Figura 2. Áreas superficiais específicas dos concentrados de fosfatos sem tratamento térmico e após tratamento térmico no forno de leito fluidizado em várias temperaturas.

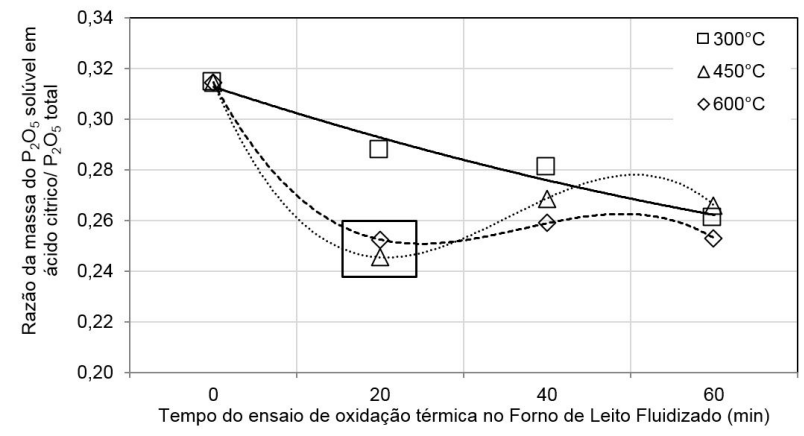

Figura 3. Razões de massa $\mathrm{P}_{2} \mathrm{O}_{5}$ solúvel em ácido cítrico $/ \mathrm{P}_{2} \mathrm{O}_{5}$ total nos concentrados de fosfatos sem tratamento térmico e após tratamento térmico no forno de leito fluidizado em várias temperaturas. foi suficiente para ter um teor de carbono orgânico total na faixa desejada, entre 1.500 a 3.500 ppm. Verifica-se também uma pequena redução na área superficial especifica nas temperaturas de $300^{\circ} \mathrm{C}$ (média de $21 \mathrm{~m}^{2} / \mathrm{g}$ ) e $450^{\circ} \mathrm{C}$ (média de $19 \mathrm{~m}^{2} / \mathrm{g}$ ), enquanto que ocorreu redução significativa a $600^{\circ} \mathrm{C}$ (média de $13 \mathrm{~m}^{2} / \mathrm{g}$ ). $\mathrm{O}$ aumento da temperatura reduz significativamente a área superficial específica e a reatividade do concentrado de fosfato em meio ácido [8]. A solubilidade do fósforo em solução de ácido cítrico reduziu apenas $5 \%$ em relação a amostra sem tratamento térmico, com razão de massa entre o $\mathrm{P}_{2} \mathrm{O}_{5}$ solúvel em ácido cítrico e o $\mathrm{P}_{2} \mathrm{O}_{5}$ total reduzindo de 0,30 para 0,25 . Com base nos resultados obtidos, foram produzidos $100 \mathrm{~kg}$ do concentrado de fosfato Bayóvar tratado termicamente, para os ensaios contínuos em mini planta piloto, em forno de leito fluidizado a $450^{\circ} \mathrm{C}$ por 20 minutos e com vazão de ar de alimentação de $10 \mathrm{~L} / \mathrm{min}\left(20^{\circ} \mathrm{C}\right)$.

A Tabela 2 mostra a composição química do concentrado de fosfato Bayóvar após tratamento térmico a $450^{\circ} \mathrm{C}$ usado nos ensaios contínuos em mini planta piloto. Não ocorreram reduções nos teores de cloreto, cádmio e enxofre total, e nem de flúor e de sódio. Os aumentos dos teores desses elementos ocorreram devido à perda de massa de água de cristalização e de voláteis durante o tratamento térmico. Como não houve redução do teor de enxofre total, conclui-se que também não ocorreram diminuições nos teores de enxofre na forma de sulfato e na forma de sulfetos. O teor de carbono orgânico total ficou dentro da faixa desejada, entre 1.500 e 3.500 ppm.

A área superficial específica do concentrado de fosfato após tratamento térmico foi de $19 \mathrm{~m}^{2} / \mathrm{g}$, redução de apenas $30 \%$ em relação à amostra sem tratamento térmico $\left(27 \mathrm{~m}^{2} / \mathrm{g}\right)$. $\mathrm{O}$ teor de $\mathrm{CO}_{2}$ foi de $4,2 \%$, valor $12 \%$ menor que o valor encontrado na amostra sem tratamento térmico $(4,8 \%)$, indicando que houve decomposição de uma pequena parte do carbonato presente na estrutura cristalina, provavelmente do carbonato de magnésio.

\subsection{Ensaios Contínuos em Mini Planta Piloto de Ácido Fosfórico}

A granulometria das amostras dos concentrados de fosfatos Bayóvar sem e após tratamento térmico $450^{\circ} \mathrm{C}$ usados nos ensaios apresentaram tamanho médio de $0,15 \mathrm{~mm}\left(\mathrm{~d}_{50}\right)$ e máximo de $0,50 \mathrm{~mm}$, conforme mostrado na Figura 4. Não foram obervadas diferenças nas distribuições

Tabela 2. Composição química do concentrado de fosfato após tratamento térmico a $450^{\circ} \mathrm{C}$

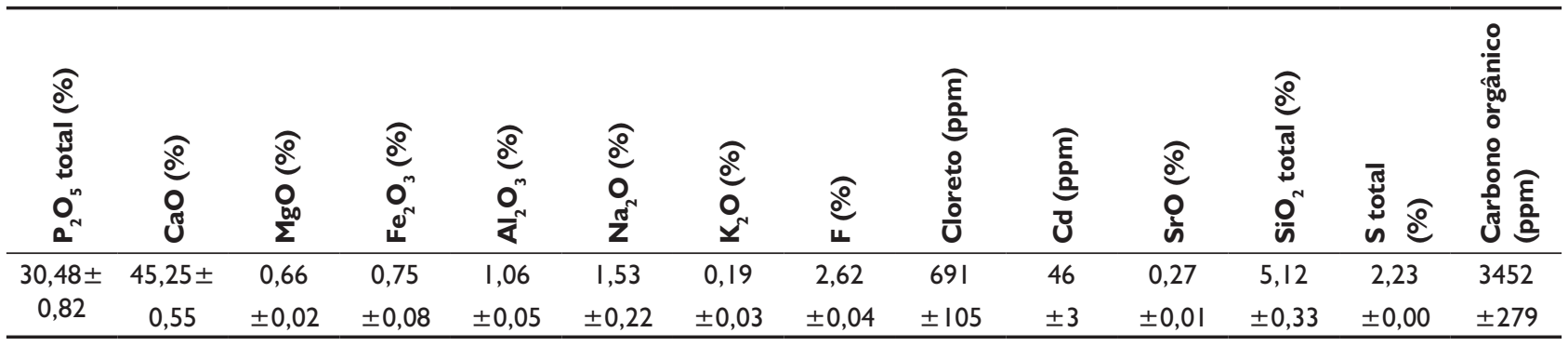


granulométricas dos dois concentrados de fosfatos usados nos ensaios contínuos em mini planta piloto de ácido fosfórico.

A Tabela 3 mostra os rendimentos de $\mathrm{P}_{2} \mathrm{O}_{5}$ no ataque, ou as extrações de fósforo do concentrado de fosfato através da lixiviação em meio sulfúrico. Em todos os ensaios foi usado caulim para mitigar o efeito corrosivo do flúor através da reação da sílica reativa presente na composição do mesmo com os íons fluoretos ( $\left.\mathrm{F}^{-}\right)$ou hexafluorsilicato $\left(\mathrm{SiF}_{6}^{-2}\right)$ presente na polpa ácida (ácido fosfórico + fosfogesso). O caulim também pode influenciar na cristalização do fosfogesso [9]. Os rendimentos médios de $\mathrm{P}_{2} \mathrm{O}_{5}$ foram de aproximadamente $95 \%$ com concentrado de fosfato Bayóvar

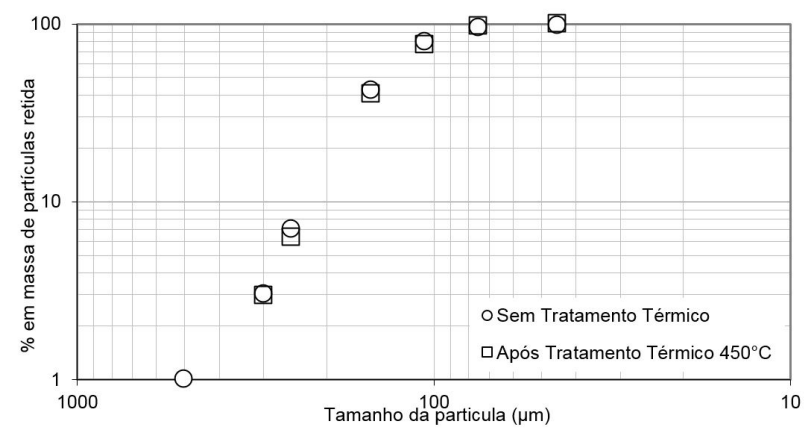

Figura 4. Distribuições granulométricas dos concentrados de fosfatos sem e após tratamento térmico em forno de leito fluidizado a $450^{\circ} \mathrm{C}$. sem tratamento térmico e de $97 \%$ com concentrado de fosfato Bayóvar após tratamento térmico $\left(450^{\circ} \mathrm{C}\right)$, portanto, sendo obtida uma recuperação em torno de $2 \%$ maior com o uso do concentrado de fosfato Bayóvar após tratamento térmico $\left(450^{\circ} \mathrm{C}\right)$.

A Tabela 4 apresenta a distribuição dos contaminantes $\mathrm{Fe}_{2} \mathrm{O}_{3}, \mathrm{Al}_{2} \mathrm{O}_{3}, \mathrm{MgO}, \mathrm{SiO}_{2}$, flúor, cádmio, cloretos, carbono orgânico, urânio, tório e $\mathrm{SrO}$ nos ácidos fosfóricos e nos fosfogessos. Não se observam diferenças significativas nas distribuições dos contaminantes para os dois concentrados de fosfato avaliados, sem e com tratamento térmico $\left(450^{\circ} \mathrm{C}\right)$. Em torno de $92 \%$ do ferro $\left(\mathrm{Fe}_{2} \mathrm{O}_{3}\right), 16 \%$ do alumínio $\left(\mathrm{Al}_{2} \mathrm{O}_{3}\right)$, $96 \%$ do magnésio (MgO), $16 \%$ da sílica $\left(\mathrm{SiO}_{2}\right), 16 \%$ do flúor (F), $61 \%$ do cádmio (Cd), $93 \%$ dos cloretos, $7 \%$ do carbono orgânico, $96 \%$ do urânio, $86 \%$ do tório e $2 \%$ do estrôncio ( $\mathrm{SrO}$ ) são direcionados para os ácidos fosfóricos. Boa parte do flúor evola do reator e pode ser coletado em um sistema de lavagem com água. Esses gases ricos em flúor, HF e/ou $\mathrm{SiF}_{4}$, são formados através das reações entre o fluoreto de cálcio ou fluorita $\left(\mathrm{CaF}_{2}\right)$ com ácido sulfúrico e da sílica reativa (principalmente silicatos, ou $\mathrm{SiO}_{2}$ ) com ácido fluorídrico (HF) [4]. Não há liberação dos cloretos na forma de gases, sendo esses fixados na solução de ácido fosfórico na forma de íons cloretos. $O$ ferro é solubilizado e forma fosfato de ferro solúvel no ácido fosfórico, o estrôncio forma sulfato de estrôncio insolúvel e a sílica na forma de quartzo tem cinética de reação lenta e permanece sem ser solubilizada. A maior quantidade de ferro no ácido fosfórico impacta

Tabela 3. Rendimentos de $\mathrm{P}_{2} \mathrm{O}_{5}$ ataque obtidos nos ensaios com concentrado de fosfato Bayóvar sem tratamento térmico e após tratamento térmico a $450^{\circ} \mathrm{C}$

\begin{tabular}{cccc}
\hline $\begin{array}{c}\text { Concentrado de Fosfato } \\
\text { Bayóvar }\end{array}$ & Condição de Ensaio & $\begin{array}{c}\text { Perdas Insolúveis no } \\
\text { fosfogesso } \\
\left(\% \mathbf{P}_{\mathbf{2}} \mathbf{O}_{\mathbf{5}}\right)\end{array}$ & $\begin{array}{c}\text { Rendimentos de } \mathbf{P}_{\mathbf{2}} \mathbf{O}_{\mathbf{5}} \text { nos } \\
\text { Ataques }(\%)\end{array}$ \\
\hline Sem Tratamento Térmico \\
$\begin{array}{c}\text { Após Tratamento Térmico a } \\
450^{\circ} \mathrm{C}\end{array}$ & $\begin{array}{c}\text { Com Caulim, Antiespumante e } \\
\text { Floculante } \\
\text { Apenas com Caulim }\end{array}$ & $0,94 \pm 0,43$ & $95,33 \pm 2,14$ \\
\hline
\end{tabular}

Tabela 4. Distribuições dos contaminantes no ácido produto e no fosfogesso obtidas nos ensaios contínuos em mini planta com concentrados de fosfato Bayóvar sem e após tratamento térmico (\%)

\begin{tabular}{|c|c|c|c|c|}
\hline & \multicolumn{2}{|c|}{$\begin{array}{c}\text { Concentrado de fosfato Bayóvar sem } \\
\text { tratamento térmico }\end{array}$} & \multicolumn{2}{|c|}{$\begin{array}{l}\text { Concentrado de fosfato Bayóvar após } \\
\text { tratamento térmico }\left(450^{\circ} \mathrm{C}\right)\end{array}$} \\
\hline & Ácido Fosfórico & Fosfogesso & Ácido Fosfórico & Fosfogesso \\
\hline $\mathrm{Fe}_{2} \mathrm{O}_{3}$ & 88 & 12 & 95 & 5 \\
\hline $\mathrm{Al}_{2} \mathrm{O}_{3}$ & 16 & 84 & 16 & 84 \\
\hline $\mathrm{MgO}$ & 97 & 3 & 95 & 5 \\
\hline $\mathrm{SiO}_{2}$ & 16 & 84 & 16 & 84 \\
\hline Flúor (*) & 17 & N.D. & 16 & N.D. \\
\hline Cd & 61 & 39 & 61 & 39 \\
\hline Cloretos & 100 & 0 & 86 & N.D. \\
\hline Carbono orgânico & 9 & 93 & 8 & 92 \\
\hline Urânio & 95 & 5 & 96 & 4 \\
\hline Tório & 86 & 14 & 87 & 13 \\
\hline $\mathrm{SrO}$ & 2 & 98 & 2 & 98 \\
\hline
\end{tabular}

N.D. Não disponível. 
negativamente no atingimento da especificação química do MAP, ou fosfato monoamônico, e no desenvolvimento operacional da respectiva unidade industrial. O MAP é produzido a partir da reação da amônia e ácido fosfórico. Os íons cloretos são bastante corrosivos, diminuindo a vida útil dos equipamentos.

A Tabela 5 mostra as taxas de filtração em toneladas de $\mathrm{P}_{2} \mathrm{O}_{5}$ por dia por $\mathrm{m}^{2}$ de área efetiva ou submetida a vácuo do filtro. Foram considerados filtro de correia com ciclo efetivo de filtração de $45 \mathrm{~s}$ e vácuo de $400 \mathrm{mmHg}$ e filtro rotativo com ciclo efetivo de 150 s e vácuo de $500 \mathrm{mmHg}$, condições essas geralmente verificadas em filtros comerciais. As melhores taxas de filtração foram obtidas nos ensaios com concentrado de fosfato Bayóvar após tratamento térmico $\left(450^{\circ} \mathrm{C}\right)$, com valores em torno de 2 vezes maior do que as verificadas nos ensaios concentrado de fosfato Bayóvar sem tratamento térmico.
A Figura 5 mostra fotos dos cristais de fosfogessos produzidos com concentrado de fosfato Bayóvar sem tratamento térmico (Figuras $5 a$ e $5 b$ ) e com concentrado de fosfato Bayóvar após tratamento térmico $\left(450^{\circ} \mathrm{C}\right)$ (Figuras 5 c e $5 \mathrm{~d}$ ). Observa-se a presença de cristais de fosfogesso no formato agulha, menor razão largura/comprimento, no ensaio realizado com concentrado de fosfato Bayóvar sem tratamento térmico e no formato tabular, de maiores dimensões ou maiores razões largura/comprimento, no ensaio com concentrado de fosfato após tratamento térmico $\left(450^{\circ} \mathrm{C}\right)$. Cristais de maiores dimensões ou no formato tabular implicam em maiores altas taxas de filtração [4].

A Tabela 6 apresenta os parâmetros médios de operação em cada condição com os concentrados de fosfato Bayóvar sem tratamento térmico e após tratamento térmico $\left(450^{\circ} \mathrm{C}\right)$. Observa-se que os teores de $\mathrm{P}_{2} \mathrm{O}_{5}$ e as densidades dos ácidos fosfóricos produzidos com concentrado de fosfato

Tabela 5. Taxas de filtração em filtro de correia e filtro rotativo obtidas nos ensaios contínuos em mini planta com concentrados de fosfato Bayóvar sem e após tratamento térmico $\left(\mathrm{t}_{2} \mathrm{O}_{5} / \mathrm{m}^{2} / \mathrm{dia}\right)(*)$

\begin{tabular}{cccc}
\hline \multicolumn{2}{c}{ Filtro de Correia } & \multicolumn{2}{c}{ Filtro Rotativo } \\
(45s de ciclo efetivo e 400 $\mathbf{m m H g}$ de vácuo) & (I50s de ciclo efetivo e 500 $\mathbf{m m H g}$ de vácuo)
\end{tabular}

(*) O ensaio com concentrado de fosfato Bayóvar sem tratamento térmico houve a adição de floculante e de antiespumante. Foi consumido caulim em ambos os ensaios.

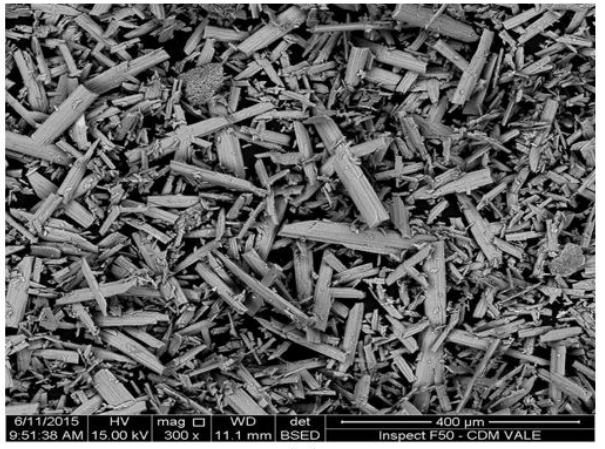

(a)

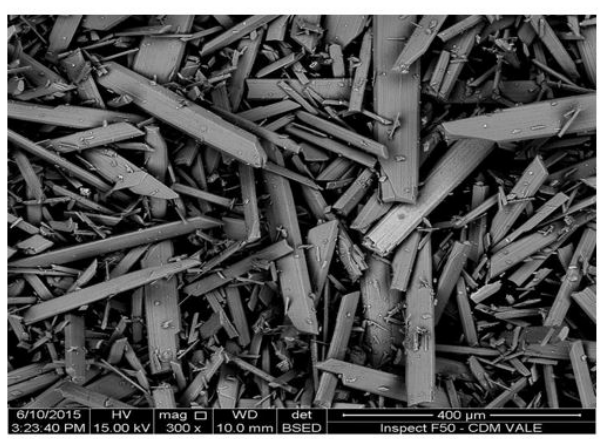

(c)

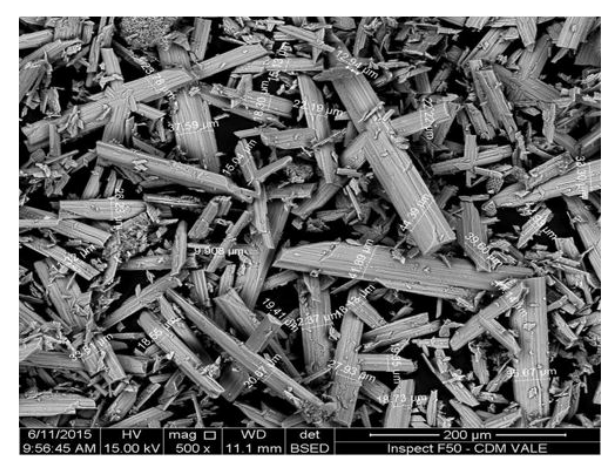

(b)

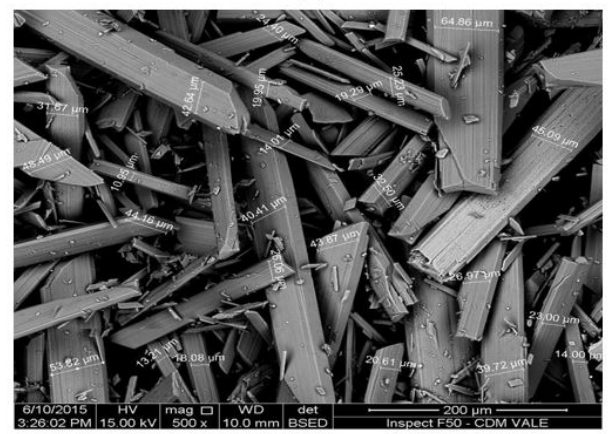

(d)

Figura 5. Fotos dos cristais dos fosfogessos obtidos com concentrado de fosfato Bayóvar sem tratamento térmico (a) e (b) e com concentrado de fosfato Bayóvar após tratamento térmico $\left(450^{\circ} \mathrm{C}\right)(\mathrm{c})$ e (d). 
Bayóvar após tratamento térmico $\left(450^{\circ} \mathrm{C}\right)$ foram maiores (28,95\% de $\mathrm{P}_{2} \mathrm{O}_{5}$ e I, $345 \mathrm{~g} / \mathrm{cm}^{3}$ a $40^{\circ} \mathrm{C}$ contra $26,32 \%$ de $\mathrm{P}_{2} \mathrm{O}_{5}$ e $1,316 \mathrm{~g} / \mathrm{cm}^{3}$ a $40^{\circ} \mathrm{C}$ ). $\mathrm{O}$ aumento da concentração de $\mathrm{P}_{2} \mathrm{O}_{5}$ no ácido fosfórico implica também no aumento da densidade do mesmo e diminui o consumo de vapor na etapa de concentração do ácido fosfórico. $\mathrm{O}$ teor de $\mathrm{P}_{2} \mathrm{O}_{5}$ no ácido de retorno variou entre 13 e $15 \%$ e densidade entre $\mathrm{I}, \mathrm{I} 50 \mathrm{e} \mathrm{I,}, 70 \mathrm{~g} / \mathrm{cm}^{3} \mathrm{a} \sim 40^{\circ} \mathrm{C}$. O teor de sólido na polpa ácida foi menor no ensaio com concentrado de fosfato Bayóvar após tratamento térmico ( $\sim 34,58 \% \mathrm{p} / \mathrm{p}$ contra $37,35 \% \mathrm{p} / \mathrm{p})$. O teor médio de sulfato total no ácido fosfórico obtido com concentrado de fosfato Bayóvar após tratamento térmico foi de 2,0\%. As temperaturas das polpas ácidas foram mantidas em torno de $77^{\circ} \mathrm{C}$, que se encontra dentro da região da rota de processo dihidrato, rota de processo mais usada na produção de ácido fosfórico [4]. O tempo de operação com concentrado após tratamento térmico foi menor $(63 \mathrm{~h})$ pelo fato da maior facilidade em estabilizar as condições operacionais da mini planta. Após 48 horas de operação, foi iniciada as medições dos parâmetros de processo sem que ocorressem grandes variações. Foi necessário tempo maior para estabilização da mini planta no ensaio com concentrado sem tratamento térmico.

A Figura 6 mostra as fotos dos fosfogessos e dos ácidos fosfóricos produzidos com concentrado de fosfato Bayóvar sem tratamento térmico (Figura 6a) e com concentrado de fosfato Bayóvar após tratamento térmico $\left(450^{\circ} \mathrm{C}\right)$ (Figura 6b). Não são observadas diferenças significativas, apresentando em ambos os casos ácidos fosfóricos e fosfogessos com tonalidades escuras.

A Tabela 7 apresenta os consumos específicos do antiespumante LIOVAC 1901, floculante FLONEX 912, ácido sulfúrico, caulim e concentrado de fosfato Bayóvar. As melhores condições foram observadas com o concentrado de fosfato após tratamento térmico $\left(450^{\circ} \mathrm{C}\right)$, sem consumos de antiespumante e de floculante e com menores consumos específicos de ácido sulfúrico $100 \%$ e de concentrado de fosfato Bayóvar de 2,672 e 3,458 por tonelada de $\mathrm{P}_{2} \mathrm{O}_{5}$ produzido, respectivamente.

Tabela 6. Parâmetros de operação com o concentrado de fosfato Bayóvar sem e após tratamento térmico em forno de leito fluidizado $\left(450^{\circ} \mathrm{C}\right)$

\begin{tabular}{ccc}
\hline $\begin{array}{c}\text { Condição de operação / Tipo de concentrado de } \\
\text { fosfato Bayóvar }\end{array}$ & Sem tratamento térmico & Após tratamento térmico (450 $\left.{ }^{\circ} \mathbf{C}\right)$ \\
\hline Horas total de operação (acumulada) & 100 & 63 \\
Rendimento de ataque $(\%)$ & 95,33 & 97,27 \\
$\mathrm{P}_{2} \mathrm{O}_{5}$ no ácido produto $(\%)$ & 26,32 & 28,95 \\
$\mathrm{P}_{2} \mathrm{O}_{5}$ no ácido de retorno $(\%)$ & 12,94 & 14,65 \\
Densidade ácido retorno $\left(\mathrm{g} / \mathrm{ml} \sim 40^{\circ} \mathrm{C}\right)$ & $1,15 \mathrm{I}$ & 1,170 \\
Densidade ácido produto $\left(\mathrm{g} / \mathrm{ml} \sim 40^{\circ} \mathrm{C}\right)$ & 1,316 & 1,345 \\
Teor de sólidos na polpa ácida $(\%)$ & 37,35 & 34,58 \\
Densidade polpa ácida $\left(\mathrm{g} / \mathrm{ml} \sim 60^{\circ} \mathrm{C}\right)$ & 1,469 & 1,526 \\
Sulfato total no ácido produto $(\%)$ & 2,05 & 2,04 \\
Temperatura da polpa ácida $\left({ }^{\circ} \mathrm{C}\right)$ & 77,6 & 77,5 \\
\hline
\end{tabular}

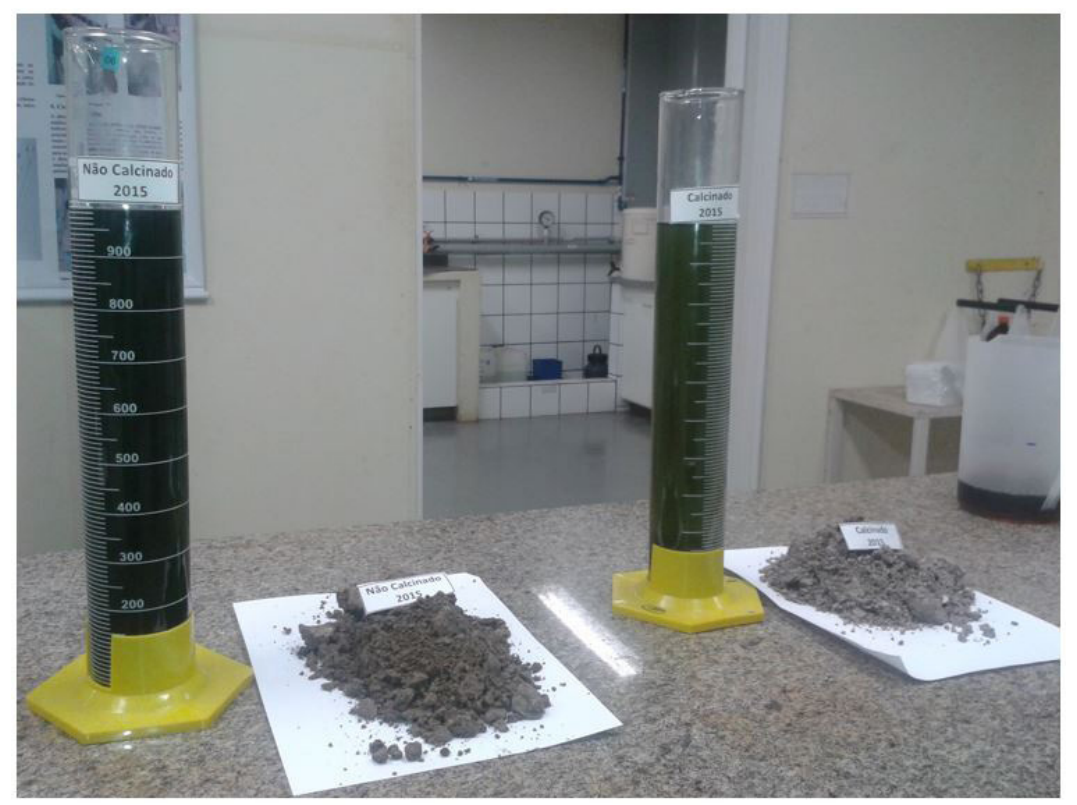

Figura 6. Fotos fosfogessos e ácidos fosfóricos produzidos com concentrado de fosfato Bayóvar sem tratamento térmico (esquerda) e após tratamento térmico em forno de leito fluidizado $\left(450^{\circ} \mathrm{C}\right)$ (direita). 
Tabela 7. Consumos específicos com concentrado de fosfato Bayóvar sem e após tratamento térmico $\left(450^{\circ} \mathrm{C}\right)$

\begin{tabular}{ccc}
\hline Consumos específicos / Tipo de concentrado de fosfato Bayóvar & $\begin{array}{c}\text { Sem tratamento } \\
\text { térmico }\end{array}$ & $\begin{array}{c}\text { Após tratamento } \\
\text { térmico (450 }\end{array}$ \\
\hline Antiespumante $100 \%(\mathrm{~kg} / \mathrm{t}$ concentrado de fosfato) & 5,33 & 0 \\
Floculante $100 \%(\mathrm{~kg} / \mathrm{t}$ concentrado de fosfato) & 0,023 & 0 \\
Caulim $(\mathrm{kg} / \mathrm{t}$ concentrado de fosfato $)$ & 16,24 & 16,28 \\
Ácido sulfúrico I00\% $\left(\mathrm{t} / \mathrm{t} \mathrm{P}_{2} \mathrm{O}_{5}\right.$ produzido $)$ & 2,888 & 2,672 \\
Concentrado de fosfato Bayóvar $\left(\mathrm{t} / \mathrm{t} \mathrm{P}_{2} \mathrm{O}_{5}\right.$ produzido) & 3,620 & 3,458 \\
\hline
\end{tabular}

\section{CONCLUSÕES}

A condição de oxidação térmica que permitiu adequar o teor de carbono orgânico no concentrado de fosfato Bayóvar para a faixa entre 1.500 e 3.500 ppm, valores geralmente observados nos concentrados de fosfatos comerciais de Marrocos e da Flórida, foi obtida em forno de leito fluidizado, temperatura de $450^{\circ} \mathrm{C}$, tempo de residência de máximo de 20 minutos e a alimentação de ar de fluidização de $10 \mathrm{~L} / \mathrm{min}\left(20^{\circ} \mathrm{C}\right)$. O tamanho médio da partícula foi de $0,15 \mathrm{~mm}$. A solubilidade do fósforo em solução de ácido cítrico reduziu apenas $5 \%$ e a área superficial específica diminuiu $30 \%$ ( 19 versus $27 \mathrm{~m}^{2} / \mathrm{g}$ ).

O concentrado de fosfato Bayóvar após tratamento térmico a $450^{\circ} \mathrm{C}$ e com teor de carbono orgânico total de aproximadamente $3.400 \mathrm{ppm}$ apresentou desempenho superior nos ensaios contínuos na mini planta piloto de ácido fosfórico ao obtido com concentrado de fosfato Bayóvar sem tratamento térmico ( $~ 8300$ ppm de carbono orgânico total), sendo observado taxas de filtrações 2 vezes maiores, menor consumo de reagentes (ácido sulfúrico e concentrado de fosfato) e não foi necessária a adição dos aditivos para redução da geração de espuma (antiespumante) e floculação da matéria-orgânica (floculante). Devido ao bom desempenho do fosfato após tratamento térmico $\left(450^{\circ} \mathrm{C}\right)$ na produção de ácido fosfórico, sugere-se a realização de ensaios contínuos em mini planta com os concentrados de fosfatos comerciais de Marrocos e da Flórida para comparação dos resultados.

\section{Agradecimentos}

Os autores agradecem a VALE e a VALE FERTILIZANTES, especialmente a Patrice Mazzoni, Keila Gonçalves e Carlos Ataíde, por permitirem a publicação desse estudo.

\section{REFERÊNCIAS}

I Mazzilli, B.P, Saueia, C.H.R. Distribution of natural radionuclides in the production and use of phosphate fertilizers in Brazil. Journal of Environmental Radioactivity. 2006;89:229-239.

2 Abdel-Zaher MA. Pysical and thermal treatment of phosphate ores - an overview. International Journal of Mineral Processing. 2008;85:59-84.

3 Baldoino RO, Martins M, Rodrigues MVT, Leal LS Fo. Influence of temperature, water quality and collector type on flotation performance of a peruvian phosphate ore. Journal of Chemistry and Chemical Engineering. 20I3;7:35I-355.

4 Becker P. Phosphate and phosphoric acid. New York: Marcel Dekker Inc.; 1983. 585 p.

5 Boumnijel I, Amor HB, Chtara C. Effect of calcinated and activated perlite on improving efficiency of dehydrate process for phosphoric acid. International Journal of Mineral Processing. 2013; 1 25: I I 2-I 17.

6 Wimberley J. Determination of low concentrations of organic carbon in phosphoric acid and phosphate rock. Analytica Chimica Acta. 1970;52: I42-145.

7 Mair A, Florence A. Thermal treatment of rock. Patent Number 4.702.896. Alabama: Tennessee Valley Authority, Muscle Shoals; 1986.

8 Silva RG, Avelar A, Brito J, Smith PA, Soares WG. Redução do teor de carbono orgânico no concentrado de fosfato Bayóvar para produção de ácido fosfórico. Tecnologia em Metalurgia, Materiais e Mineração. 2016; 13(3):270-278.

9 Theys T, Roblin B. Crystal habit modification in wet process phosphoric acid production. In: International Fertilizer Association. Proceedings of the IFA Technical Conference; 2002 Sep 24-27; Chennai, India. Paris: IFA; 2002.

Recebido em: 28 Ago. 2016

Aceito em: 12 Fev. 2017 